\title{
AC 2011-517: PROJECT-BASED RESIDENCY COURSE FOR ONLINE GRADUATE PROGRAM
}

\author{
Bimal P. Nepal, Texas A\&M University \\ Dr. F. Barry Lawrence, Texas A\&M University
}

Dr. Barry Lawrence holds the Leonard and Valerie Bruce Leadership Chair, the Program Director of the Industrial Distribution Program, Director of the Thomas and Joan Read Center, and Director of the Global Supply Chain Laboratory at Texas A\&M University.

As a faculty member of the Industrial Distribution Program he is involved in graduate, undergraduate, and professional continuing education teaching activities, funded research projects, publications and industry presentations. His teaching activities surround classes in manufacturer/distributor relationships, Supply Chain Management, distributor profitability, and distribution strategy. He is a frequent speaker for distribution associations, buying groups and companies on topics ranging from distributor profitability, distribution growth \& market share, pricing optimization, inventory asset management, sales and marketing optimization, global distribution, and numerous other topics.

Dr. Lawrence is a fellow of the National Association of Wholesaler Distributors (NAW) institute and the author of four books on distributor competitiveness. Dr. Lawrence holds a Ph.D. in Information and Operations Management from Texas A\&M University, an M.B.A. from Texas State University and a B.B.A .in Finance from University of Texas at Austin. He has more than 10 years of industry experience in sales and retail business before joining Texas A\&M.

(C)American Society for Engineering Education, 2011 


\section{Project-based residency course for online graduate program}

\section{Introduction}

Distance based programs are expanding beyond liberal arts and business schools all across the world. Many engineering and engineering technology programs are currently offering distance based graduate programs to attract working professionals. While it is widely recognized in the academic community that project-based learning (PBL) can have lasting impact on the student's learning compared to that by traditional topic-based learning (TBL), not many institutes have opted this approach especially in the online degree programs. In this paper, we present a graduate level course in industrial distribution program at the Texas A\&M University that is especially designed for mid to senior level executives working at the distribution firms across the world. The Masters in Industrial Distribution (MID) program is housed within the Department of Engineering Technology and Industrial Distribution. There are several unique features of the MID program: first, this is the only executive MID program in the Country; it is purely distance based program including two residency weeks in as many years; it is a cohort program meaning that a particular batch of students will take the same courses together in each semester; it includes a global trip as a part of curriculum; and the students work on several project-based learning courses.

The case study of the course this paper presents is a one week long project based course that is offered during the residency week of the second year of the program. Students work on a company-sponsored real world project. At the end of the week the students present their analysis and results to faculty and industry executives based on which their performance is measured. In this paper, we present the course objectives, course design, and grading policy. Results of student learning outcomes survey are also presented in the paper.

The remainder of the paper is organized as follows. In section II, we present a brief discussion on the different learning approaches that are out there in practice. Section III describes the andragogical model for adult learning. In section IV, we present our proposed framework for project based learning including objectives, design, and grading policy of the course. Section V presents the student learning survey. Benefits of a residency class are discussed in Section VI. Finally, section VII summarizes the paper with some concluding remarks.

\section{Topic-based learning, problem-based learning, and project-based learning}

Yousuf et al. ${ }^{1}$ define topic based learning as the mode of instructional delivery and learning based on the sequence of materials presented in a textbook. The authors suggest that in traditional topic based learning, the "knowledge transmission" depends upon the instructor and how he or she designs and delivers the material given in the text book. It has little correlation with what is the contemporary need of the industry. On the other hand, project based learning represents more active learning ${ }^{2}$. Project based learning is sometimes viewed as problem based learning, especially in the medical education as both approaches require self-direction and collaboration among multiple disciplines ${ }^{3}$. However, there are some clear differences between the two learning approaches. For example, according to Perrenet et al. ${ }^{4}$, project work is more about the application of knowledge whereas the problem based learning generally represents the 
acquisition of knowledge. Further, project work also requires the time and resource management and the work breakdown structure. As a result, project based learning take relatively longer time than the problem based or topic based learning approaches require ${ }^{3}$.

Amount and nature of project work can vary from one engineering discipline to another. For example, a mechanical engineering design project and the civil engineering project may involve physical modeling and experiments whereas an industrial engineering may consist of simulation models. However, regardless of discipline all project works require integration of knowledge from multiple courses. Particularly in the MID class projects to be described in this paper, successful completion of project will also require a real world work experience in addition to prior knowledge of other industrial distribution (ID) courses.

In summary, while it is important to have academic rigor based on theory offered by traditional topic based learning, it is also important to recognize the necessity of innovative pedagogical approach with hands on tools offered generally in project-based learning ${ }^{5}$. This is especially important if the student population is relatively mature and experienced as described in the following section.

\section{Andragogy: the art and science of adult learning}

The student profile of our MID class is very diverse and mature with respect to areas of work experience and age of the students. The average work experience of a student is about 10 years and the average age is about 35 years. In this section we review well known work of Malcom Knowles that describe the adult learning behaviors. Knowles ${ }^{6}$ suggests that an adult is more problem oriented than subject-oriented in learning. The andragogy proposed by Knowles describes the art and science of how adults learn with following assumptions (quoted from Merriam et al. ${ }^{7}$ ):

a. As a person matures, his or her self concept moves from that of a dependent personality toward one of a self-directing human being.

$b$. An adult accumulates a growing reservoir of experience, which is a rich source for learning.

c. The readiness of an adult to learn is closely related to the departmental tasks of his or her social role.

d. There is a change in time perspective as people mature-from future application of knowledge to immediacy of application.

e. The most potent motivations are internal rather than external(see original reference in Knowles and Associates, 1984)

f. Adults need to why they need to learn something.

For detail assumptions and further information on Knowles andragogy, readers are referred to Merriam et al. ${ }^{7}$ (p.84). The important message of the above-mentioned andragogy is that the way adult learn is different from their traditional counterparts, the fresh college students. In this regard, we find the project based learning approach meeting the need of adult learners better than the traditional topic based learning model. 


\section{Framework for project based learning and its relevance to an online graduate course}

Constructivism ${ }^{7}$ provides a theoretical foundation for a project based learning course. It is a process of active learning which focuses on students' learning rather than an instructor's performance and teaching tools. According to Mills $^{3}$, "it is an active process in which teaching is integral with supporting learning; listening to and understanding students' knowledge concepts, adopting teaching approaches that promote conceptual change and assessing learning in a manner that supports these changes". While it is widely recognized in the academic community that project based learning can have lasting impact on the student's learning compared to that by traditional topic based learning, not many institutes have opted this approach especially in the online degree programs. On the other hand, with advancement in Internet technology the online delivery of course has been a commonplace but it is very difficult to offer a fully project-based course online especially if the project sponsoring corporation and students live in different time zones. One way to overcome this challenge is to create a residency course on campus where all students and instructors can be in the same room. It also facilitates the class to interact with the company that is sponsoring the project more effectively.

In this paper we present a one week long project based course that is offered during the residency week of the second year of our MID program. The title of the course is "IDIS 621: Distributor Process" in which students work in teams on a company-sponsored real world project. At the end of the week the students present their analysis and results to faculty and industry executives based on which they receive their grades. Following sections describe the objectives and design of the course.

\section{A. Course Objectives}

This is a research and analysis centric project based course, which builds on the knowledge gained from the earlier MID courses. It involves practical applications of research methodologies and best practices in distribution environment. Students develop a solution for the participating firm by conducting a research project with a scientific analysis approach. The project is designed to focus on managerial and/or technical decisions where the students will first analyze a research paper created on the distribution company that is sponsoring the project, and then perform a full analysis to develop a practical yet scientifically validated solution for the company.

Upon successful completion of the course, students will be able to:

- Apply the scientific research approach to practitioner problems in industry

- Select the appropriate data type and the scales for measuring the industry data.

- Demonstrate systematic thought processes used in scientific thinking and assessment of current industry practice

- Identify, describe and implement the key steps in the analysis process, including problem identification, analysis methodology, data collection, analysis of findings, and written and oral presentation of results.

- Assess the current business processes of a distribution firm and identify the common, good and best practices thereby make recommendation to achieve the best practices 


\section{B. Course Design}

This is a three-credit course offered in beginning of the second year of the MID program during the residency week. It is designed as a weeklong intensive course in which the students work on it from Monday through Friday, 8:00 AM to 5:00 PM. Figure 1 depicts the design and schedule of the course.

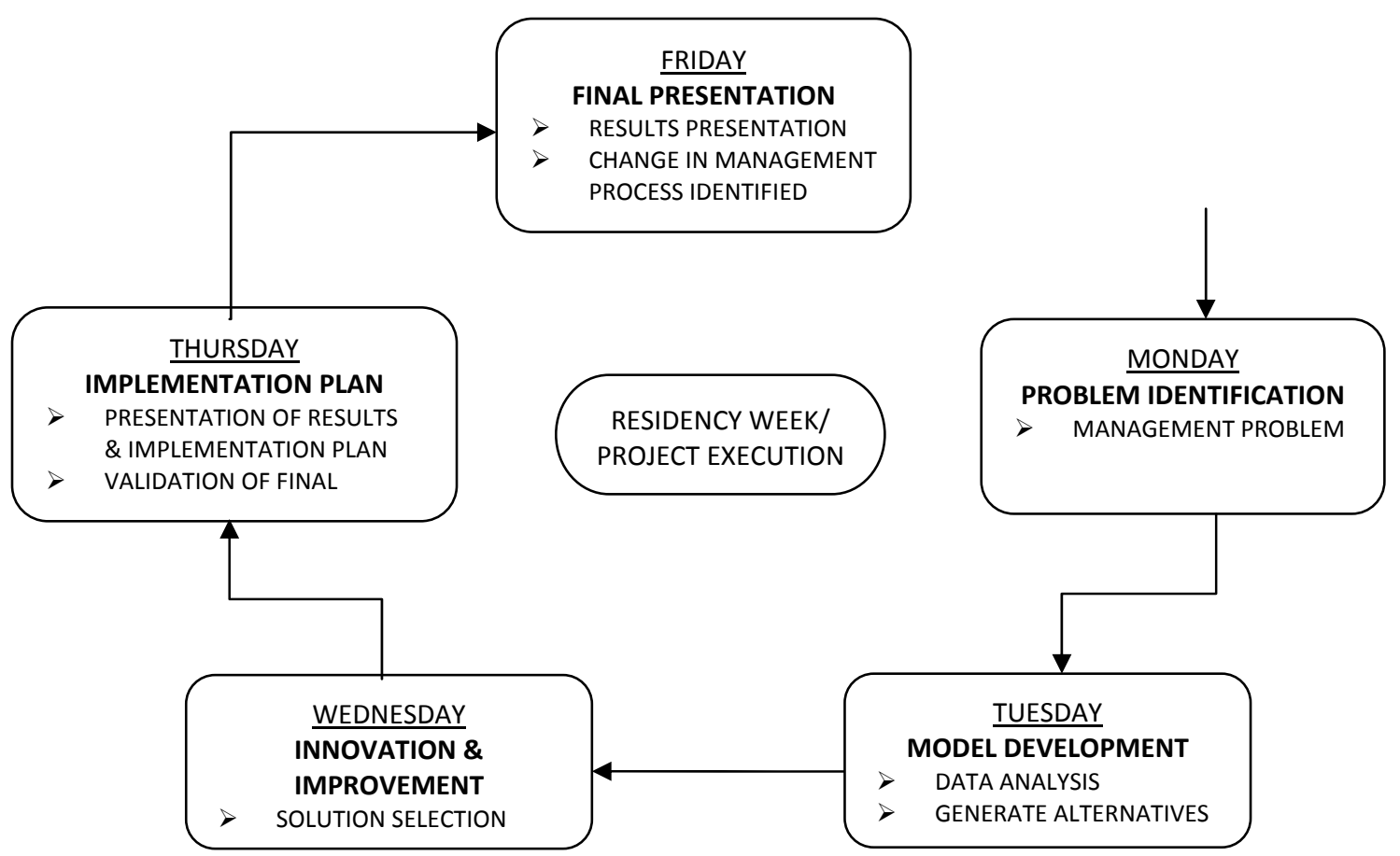

Figure 1: Course schedule for residency week

Although not shown in the above figure, the actual course process starts prior to residency week. The students receive their course packet which includes the course outline including expectations and mode of instruction and background of company at least one month before the residency week. After receiving the packet, the students will form a team and identify their tentative area of study. For example, the study areas cover seven basic processes of a distribution firm as described in Lawrence et al. ${ }^{8}$. The seven processes include sourcing, store, stock, sales, support services, shipping, and supply chain planning. In a typical class, there will be four to five groups. Each group will take one or more processes depending upon the nature of the process. The instructor will make the final call on the group assignments based on the students interests and perceived workload in each area of study. They will also have to prepare a 5-page long report on their initial analysis and proposed methodology and expected results. After the students arrive on campus for the residency week, they will follow the schedule shown earlier in Figure 1.

During the residency week, on day 1 (Monday), the students will meet with instructors in the morning to update him/her with their progress. Thereafter, the students along with the instructor travel to visit the company facility. The objective of this visit is to understand the current business process and refine their problem statement. They also collect the necessary data for 
their project. More importantly, they establish the contact with industry in case they need more data for the analysis.

On Tuesday, the students spend their time in model development and data analysis. They generate alternative solutions for the company with some guidance from the instructor and supply chain systems lab (SCSL) researchers (The SCSL is a world class global supply chain research laboratory housed within the Industrial Distribution Program). Students will also be in constant communication with the sponsoring company to validate the data and their solutions. Based on the feedback from the company and the SCSL researchers, the students will continuously improve their solutions. Thus the Wednesday marks the innovation or solution selection day. Among other things, the main criterion for solution selection is return on investment (ROI) for the company. Furthermore, the students will work on the draft presentations and implementation plan on Wednesday. On Thursday, they will present the results and implementation plan to faculty and SCSL project managers. Typically, these presentations are enormously interactive and draw immense critiques and suggestions. Students generally work until late hours on Thursday to incorporate the feedbacks and prepare the final presentation for the project sponsor on Friday. The final results and recommendation for implementation and change management are presented on Friday morning to a team of senior executives from the sponsoring company. Such team includes the company CEO, senior vice presidents, and the functional managers. In the afternoon of Friday, the students meet with the instructor to wrap up the course.

\section{Course Grading Policy}

The course grading is divided into two parts: research paper analysis and final management presentation. Each part carries 100 points. The standard university scales are applied to assign A, B, C, D, and F grades. The research paper analysis is due three weeks before the residency week to provide the students with necessary feedback on the analysis approach and expected results.

\section{Students Learning Survey}

In this research, we conducted a survey of all the former MID students who had taken this course, especially those who worked on the company sponsored projects. The integration of company sponsored project in the "Distributor Process I" course was started in 2007. Therefore, the survey included the students of class of 2008 through 2011. The objective of survey research was to understand the student's feedback on the effectiveness of the course materials and project based delivery structure on their learning. The sample topics covered in the survey questions were as follows:

- Student learning experience of the course

- What did they like the most about the course?

- Comparison of project based learning approach versus traditional approach

- Areas for improvement for future

- Feedback on benefits and challenges of a residency class

The survey questions and data collection methods were reviewed and approved by the Texas A\&M University Office of Research Compliance. Although the response rate of the survey was little low (about 11\%), there was an overwhelming consensus on the responses. For example, all 
of them had very positive view of their learning experience. Below is a quote from one student about the learning experience:

"Enhanced learning on how to effectively conduct a research product, through the use of "real world" data and information. Working with company executives to identify areas for improvement, within their

Organization, in today's environment, as opposed to drudging through an updated case study, proved to be much more valuable than anything I had ever been exposed to."

Students also liked the situations they were provided with which matched the contemporary business climate that they were working in. There was unanimous agreement on the project based learning approach having more impact on their learning ability than that via traditional topic based learning method. Here is anther quote from the survey response on the positive aspects of the course:

"The best experience was having all the real numbers and problems to deal with, not just fake or developed ones. Also, dealing with the managers of the organization was unique and it gave a better feel and more knowledge to help develop solutions wit."

On the areas for improvement, majority of the students liked the way it was handled currently. One of the students from the class of 2010 had suggested that the project should have a focused problem as opposed to multiple issues. While the suggestion has merit in that the project problems should be defined with clear objectives and scope, the intent of the course is to address multiple issues. The rationale for having multiple issues are as follows: first, we believe that the students should take a systems or holistic approach to find the root causes of the problem as opposed to single aspect such as inventory management because issues are generally interrelated; second, typical current class size is 15 (meaning four to five teams) with different business backgrounds so they can tackle multiple issues simultaneously; and lastly, the course focuses on seven specific processes of a distribution business as mentioned earlier.

\section{Benefits of residency class}

Prior research has highlighted the value of residency class in an online degree program ${ }^{9}$. Our survey results have further validated that finding unanimously. Students have noted the several benefits of residency class that brought all the students on the University campus together for one week. The most important benefit was the opportunity to interact with other cohorts, faculty, and supply chain research lab staffs. The students have much appreciated the opportunity to interact with the industry executives and work as an "outside consultant". Some of the other benefits as noted in the survey were as follows:

- Formed program structure that kept students on task

- Opportunity to visit the University campus, understand the traditions, and tour the campus including the foot ball stadium

- Ability to review real world operations and recommend best practices to a real company

- The seven S processes that can applied to any other businesses beyond distribution 


\section{Conclusions}

Although the law and business schools worldwide have been using the analysis of real world or pseudo case studies in their curriculum for a long time now, such practice in engineering education is not a common practice. In the globalized economy of $21^{\text {st }}$ century, the corporations are seeking a specialized expertise in their employees, which cannot be acquired through textbook only. It requires a lot of hands-on skills that normally come through industry projects ${ }^{10}$.

This paper has presented a case study of a project based residency course that is being offered in one and only online executive MID program at the main campus of Texas A\&M University in College Station, TX. It provided an in-depth review of the various learning approaches for student learning such as topic based, problem based, and the project based approaches. The survey results of former students showed that the project based approach involving real world business problems had far more and long lasting learning impacts than the traditional topic based learning approach. The survey results also reiterated the benefits of residency course in an online degree program.

\section{Bibliography}

1. Yousuf, A., Mustafa, M., Cruz, A. D.L. (2010). Project based learning, Proceedings of the 2010 American Society for Engineering Education Annual Conference \& Exposition, June 20-23, Louisville, KY, USA.

2. Bayles, T.M. (2005). Project based learning design pro projects for introduction to engineering design courses, Proceedings of the 2005 American Society for Engineering Education Annual Conference \& Exposition, June 12-15, Portland, OR, USA.

3. Mills, J. (2002). A case study of project-based learning in structural engineering, Proceedings of the 2002 American Society for Engineering Education Annual Conference \& Exposition, June 16-19, Montréal, Quebec, Canada.

4. Perrenet, J.C., Bouhuijs, P.A.J. and Smits, J.G.M.M., 2000. The Suitability of Problem-Based Learning for Engineering Education: Theory and Practice, Teaching Higher Education, 5 (3), 345-358.

5. Esche, S.K., Hadim, H.A. (2002). Introduction of project based learning into mechanical engineering courses, Proceedings of the 2002 American Society for Engineering Education Annual Conference \& Exposition, June 16-19, Montréal, Quebec, Canada.

6. Knowles, Malcolm S. 1980. The Modern Practice of Adult Education; From Andragogy to Pedagogy, Englewood Cliffs, NJ: Cambridge Adult Education.

7. Merriam, S.B., Caffarella, R.S., Baumgartner, L.M. (2008). Learning in Adulthood: A Comprehensive Guide, Third Ed., San Francisco, CA: John Wiley \&Sons.

8. Lawrence, F.B., Gunasekaran, S., Krishnadevarajan, P. (2009). Optimizing Distributor Profitability: Best Practices to a Stronger Bottom Line, Washington, D.C.: NAW Institute for Distribution Excellence.

9. Descoteaux, T., Muckerman, D., Sabol, S. (2009). The importance of an on-campus residency experience in distance-education programs, Proceedings of the 2009 American Society for Engineering Education Annual Conference \& Exposition, June 14-17, Austin, TX, USA.

10. Viswanathan, S., Evans, H. (2009). Harnessing industry collaboration in developing graduate-degree programs, Proceedings of the 2009 American Society for Engineering Education Annual Conference \& Exposition, June 14-17, Austin, TX, USA. 